DOI: 10.12957/demetra.2016.21995

\title{
Alimentação, corpo e subjetividades na Educação Física e na Nutrição: o ranço da adiposidade e a ascensão dos músculos
}

\section{Food, body and subjectivities in Physical Education and Nutrition: rancidity of adiposity and the rise of muscles}

Juliana Brandão Pinto de Castro ${ }^{1,2}$

Rafael da Silva Mattos'

Michelle Delboni dos Passos²

Fernanda Silva Dias de Aquino ${ }^{3}$

Jeferson José Moebus Retondar ${ }^{4}$

Anderson dos Santos Machad $0^{5}$

1 Universidade do Estado do Rio de Janeiro, Instituto de Educação Física e Desportos, Programa de Pós-Graduação em Ciências do Exerćício e do Esporte. Rio de Janeiro-RJ, Brasil.

2 Universidade do Estado do Rio de Janeiro, Instituto de Nutrição, Programa de PósGraduação em Alimentação, Nutrição e Saúde, Núcleo de Estudos sobre Cultura e Alimentação. Rio de Janeiro-RJ, Brasil.

${ }^{3}$ Universidade Federal do Rio de Janeiro, Programa Interdisciplinar de Pós-Graduação em Linguística Aplicada. Rio de Janeiro-RJ, Brasil.

${ }^{4}$ Universidade do Estado do Rio de Janeiro, Instituto de Educação Física e Desportos. Rio de Janeiro-RJ, Brasil.

${ }^{5}$ Universidade Federal do Rio Grande do Sul, Programa de Pós-Graduação em Saúde Coletiva. Porto Alegre-RS, Brasil.

Correspondência / Correspondence Juliana Brandão Pinto de Castro julianabrandaoflp@hotmail.com

\section{Resumo}

O objetivo deste artigo é discutir questões relativas à imagem corporal no universo de estudantes dos cursos de graduação em Educação Física e Nutrição de uma universidade pública no município do Rio de Janeiro. Trata-se de estudo de natureza socioantropológica, situado no campo da Saúde Coletiva, cuja estratégia metodológica consistiu em articular observação participante e entrevistas informais e formais com esses discentes. Observou-se que há uma pressão para que sejam modelos de boas práticas alimentares e corporais, ou seja, comportamentos considerados saudáveis, além de apresentarem uma imagem corporal concernente com os padrões estéticos vigentes, discurso que predomina entre eles nos espaços acadêmicos e fora destes. Valores relativos a juventude, sexo e estética corporal são aí mobilizados e relacionados à convivência social, às posições de distinção na sociedade fortemente hierarquizada, reação às normas e regras sociais, entre outros aspectos na sociedade de consumo, onde o culto à imagem do corpo tende a ser hegemônico.

Palavras-chave: Educação Física e Treinamento. Ciências da Nutrição. Estudantes. Imagem Corporal. Saúde Coletiva.

\section{Abstract}

The aim of this paper is to discuss issues related to body image among undergraduate students in Physical Education and Nutrition programs at a public university in the city of Rio de Janeiro. This study has a socio-anthropological nature in the field 
of Public Health. The methodological strategy was to articulate participant observation and informal and formal interviews with these students. We found that the students feel pressured to be role models of good eating habits and body practices; in other words, to have behaviors considered as healthy. In addition, they must have a body image that meets the current esthetic standards. This is a discourse that prevails among them, both inside and outside the academic environment. Values relative to youth, sex and body esthetics are mobilized in such environment and associated with social life, distinctive positions in a strongly hierarchical society, and reactions to social norms and rules, among other features in the consumer society, where body image worship tends to be hegemonic.

Key words: Physical Education and Training. Nutritional Sciences. Students. Body Image. Collective Health.

\section{Introdução}

A imagem do corpo e, por conseguinte, o capital corporal assumem valor de destaque no imaginário social da Pós-Modernidade, período que abrange os séculos XX e XXI. ${ }^{1,2} \mathrm{O}$ corpo não é um dado inequívoco, mas efeito de uma elaboração social e cultural, onde as sociedades escolhem determinados atributos nos quais ele deve estar enquadrado para que possa ser considerado "bonito" ou adequado, submetendo-o à educação e a diversas medidas estéticas, físicas e até cirúrgicas para se adaptar ao padrão. ${ }^{3,4}$

O corpo atlético e, em especial, o "sarado", com a hipermaximização da definição e hipertrofia muscular, são valorizados no imaginário contemporâneo, enquanto que o corpo magro e, com maior ênfase, o gordo, são alvo de estigma e constantemente abordados por iniciativas que estimulam a adaptação ao padrão hegemônico. Diversos são os programas e quadros televisivos ${ }^{\mathrm{a}}$ que prometem oferecer alternativas para que indivíduos fora das medidas consideradas saudáveis possam adquirir a meta estabelecida por meio da readequação alimentar e principalmente pela prática de exercícios físicos. Não obstante, o gordo, na sociedade atual, é visto não apenas como

a Como exemplo podemos citar o quadro "Medida Certa”, no programa Fantástico da TV Globo, que oferecia um acompanhamento de celebridades e anônimos por um período de três meses para adequação das medidas corporais sob a supervisão de especialistas, bem como outros quadros como "SOS Mais Você", na mesma rede televisiva, que oferecia ações estéticas como procedimentos cirúrgicos com a mesma finalidade. Em programas como "Além do peso", na Record, e "Quem perde ganha”, no SBT, só para citar os canais abertos, transformaram a busca por um corpo perfeito em reality shows de sucesso, que repercutiram amplamente o modelo corporal hegemônico da magreza e dos músculos em evidência. 
física, mental e socialmente doente, mas apontado como incapaz, preguiçoso, doente, viciado em comida, descontrolado e com raciocínio inferior, já que pouco faz para se ajustar ao novo padrão. ${ }^{5,6}$

No mundo globalizado, observa-se cada vez mais uma homogeneização nas relações sociais. A estética corporal se estabelece, deste modo, como um instrumento que também foi incorporado nas relações de consumo, sujeitando-se a padronizações de comportamento e normatização. ${ }^{7}$ Como afirmam Lipovetsky \& Serroy, ${ }^{8}$ o mesmo modelo de beleza é difundido globalmente pela publicidade, pela moda e pelas marcas de cosméticos. No caso das mulheres, eles identificam que o ideal de robustez e força das trabalhadoras das comunidades rurais deu lugar a uma estética feminina sexy e longilínea baseada em regimes alimentares, exercícios físicos e até em procedimentos cirúrgicos. Elas ainda conservam características locais, mas que estão dentro da lógica unificada, o chamado "glocalizado", a adaptação de aspectos locais para consumo em outras comunidades de forma massiva. Para tanto, os padrões de medidas corporais precisam seguir semelhanças para que possam ser aplicados em escala global, buscando minimizar a diversidade de opções.

Nessa sociedade de consumo, ancorada no mercado, na propaganda e no marketing, a espetacularização da imagem corporal é sobejamente divulgada nas diversas mídias. Conforme observado por Luz et al., ${ }^{9,10}$ as revistas utilizam em suas capas uma proporção muito maior de modelos com corpos dentro dos padrões estéticos considerados hegemônicos em relação a figuras que apresentem outras medidas corporais. Ao combinarem imagem e palavra, em simbiose, criam uma estratégia que reforça a retórica da imagem. A aliança imagem/palavra é a chave para construir e veicular a mensagem, que deve convencer o público de sua importância, e levá-lo a adquirir um produto, hábito ou comportamento que orientará suas ações em face da vida e da saúde.

Em diversos momentos, as revistas adotam, no tom do discurso, uma perspectiva retórica, direcionando o leitor para práticas condizentes com a normatividade biocientífica e para as atividades recomendadas pelas reportagens, infundindo, ao mesmo tempo, um temor difuso de que algum mal à saúde - ou à vida - suceda, em caso de não seguimento de tais práticas, enfatizando o medo coletivo de "punição" se as regras e normas de conduta apresentadas não forem obedecidas. Foucault chamou de biopoder, o conjunto de relações de poder/saber que incidem sobre a vida, normatizando-a e controlando-a ininterruptamente. Nessa perspectiva, a vida deve procurar se ajustar a essas regulações, buscando a "boa saúde". ${ }^{11-14}$

Em diversos momentos, a manipulação das imagens para os meios eletrônicos por programas gráficos como Photoshop, entre outros, busca valorizar aspectos importantes, muitas vezes atingindo características de perfeição do corpo ou do objeto apresentado. O uso exagerado dessa técnica em várias situações provoca situações que fogem aos encontrados na vida real, claramente obra da alteração digital. Esse recurso é percebido pelo público, que muitas vezes não reconhece como possível tal condição. Os próprios modelos e atrizes fotografados para capas de revistas de fitness, 
moda e em ensaios sensuais, dizem que não se reconhecem diante de tantas alterações em atributos como luminosidade/brilho, intensidade de cores, formas perfeitas.

Ainda que apresentem proporções fora do possível para os padrões normais, a força dessas imagens em capas e programas de televisão ajuda a consolidar, no imaginário da população, determinados tipos ideais que devem ser perseguidos enquanto alimentação correta, estrutura corporal e hábitos saudáveis. Nesse compartilhar de imagens, são reforçadas representações sociais que difundem esquemas mentais coletivos e individuais, elaborados a partir das relações sociais vigentes. ${ }^{15}$ Com isso vão sendo condicionados padrões de atitudes, sentimentos, ações e interações, o que implica necessariamente um aspecto subjetivo dessas representações, isto é, de absorção, interiorização e elaboração pelos sujeitos nas mais diversas situações de vida. ${ }^{15,16}$

Essas representações sociais também são vividas por grupos, adquirindo um aspecto objetivo, isto é, de natureza social coletiva, portanto, cultural, sujeito à historicidade da mudança, tendendo a se associar e se transformar em concepções simbólicas que se ancoram e solidificam nos diversos grupos e classes sociais, constituindo verdadeiros sensos comuns estáveis, de difícil transformação histórica. $^{15,17}$

Podemos citar, como exemplo de representação social que é comumente veiculada na relação entre o corpo feminino e a alimentação, uma matéria veiculada pela revista $V_{e j a}{ }^{18}$ cuja capa apresenta uma mulher de biquíni, ao lado do texto: "A estética do risco: as dietas, suplementos e malhação específicos das mulheres que desafiam o senso comum e levam o corpo ao limite da magreza saudável”.

De acordo com a matéria, a união de duas características - a barriga negativa ${ }^{\mathrm{b}}$ e o abdômen trincado - conforma o novo padrão estético minimalista do corpo do século XXI, marcando a representação vigente de beleza a ser perseguida. O ideal de (nano)beleza apresenta um visual conflitante: um corpo atraente - para os tempos atuais -, bem cuidado e saudável, porém no limite máximo do que seria interpretado como uma pessoa doente. Talvez o arcabouço de músculos, que disfarça o pouco peso, confira um aspecto normal, do tipo que é possível imitar. ${ }^{19}$

Percebemos o caráter discursivo das produções midiáticas como práticas sociais, responsáveis pelo processo de construção e circulação de significados sobre determinado tema. São socialmente constituídas por grupo(s) específico(s), mediados a partir da seleção e reconfiguração de determinados repertórios temáticos, tornando possível a produção de sentidos e versões diversas sobre si e o mundo a sua volta. ${ }^{20}$

Tais sentidos são, muitas vezes, tomados como verdade pelo público em virtude de uma correspondência, no senso comum, entre representação e verdade. Mas sabemos que o sujeito

b A barriga negativa tem uma aparência côncava, apresentando certa curva para dentro. 
do conhecimento está inserido na sociedade que o toma por objeto. A mídia contribui para a solidificação e a divulgação de um tipo específico de identidade; promove um primeiro contato motivador de um tema, tendências, avanços científicos e tecnológicos com o público leitor. ${ }^{21}$

A pesquisa realizada por Ribeiro ${ }^{22}$ com homens (leitores ou não) a respeito das capas e reportagens da revista Men's Health constatou que o corpo em forma estética (muscular) tem preponderância sobre a saúde, pois segundo os entrevistados, entre eles o editor da revista, ao adquirir uma identificação com o padrão estético corporal apresentado pela publicação, "na medida em que você tem um corpo mais estruturado com músculos mais condicionados, você tem mais energia para fazer o que você quer da vida. Portanto, você tem mais bem-estar". 22

Conforme ressalta Sabino (p. 144), ${ }^{23}$ "não se trata aqui de tomar a doxa midiática como padrão de conhecimento sociológico, mas de levar em conta o surgimento de novas tendências e posturas sociais que a mídia expressa”. Percebemos, então, que as mulheres, que antes almejavam a magreza, agora também anseiam o perfil atlético, outrora valorizado e cultuado apenas pelo público masculino. O que tem sido buscado nas academias, por exemplo, é um corpo ausente de gordura; um corpo com mais massa magra do que um corpo magro. ${ }^{24}$ Entretanto, nos questionamos: que padrão estético é este que coopta mulheres e homens de variadas idades e classes sociais? Que imagem corporal é esta que virou objeto de desejo, mas que parece um ideal inalcançável para os reles mortais? Que ideal é este que faz com que o padrão estético muitas vezes esbarre diametralmente com a saúde, mas que, em outros momentos, faz com que ambos pareçam queridos amigos de infância? Por fim, como os estudantes da área da saúde lidam com essas questões?

Diante de tais interrogações, as linhas a seguir têm o objetivo de discutir - sem a pretensão de esgotar - os sentidos e significados imbricados na imagem corporal no universo dos estudantes dos cursos de Educação Física e a Nutrição, onde o culto ao corpo - mais especificamente, à imagem do corpo - é hegemônico.

\section{Percurso teórico e metodológico}

Este artigo é fruto de um estudo socioantropológico mais amplo, no qual a preocupação metodológica reside na descrição, compreensão e interpretação de fenômenos observados em dois grupos específicos inseridos na área das Ciências da Saúde: os discentes dos cursos de graduação em Educação Física e Nutrição de uma universidade pública localizada no município do Rio de Janeiro. Lançamos sobre esses graduandos um olhar crítico a partir de opções teórico-conceituais atinentes às obras do sociólogo alemão Max Weber. ${ }^{25,26}$

c A Men's Health (lançada no Brasil em 2006) tem como foco central ser uma revista de serviço para o público masculino, heterossexual, de classes média e alta, com temáticas voltadas para o corpo, fitness, estética, beleza, moda, saúde e sexualidade. ${ }^{22}$ 
Para condução deste estudo, elegemos a estratégia metodológica de articular observação direta e participante, ${ }^{27-29}$ além de entrevistas informais e em profundidade ${ }^{30,31}$ com graduandos de Educação Física e Nutrição, que foram gravadas e transcritas. Para contemplar o escopo da pesquisa, elencamos como locais de observação os diversos espaços da universidade, incluindo corredores, salas de aula, cantinas, bibliotecas, ginásio, academia e elevadores, além dos arredores da faculdade. Diferentes locais de observação foram utilizados, a fim de enriquecer a pesquisa, conforme preconizado por alguns autores. ${ }^{32-34}$

As entrevistas formais foram realizadas em salas de aula da universidade, onde os entrevistados concordaram em preencher o Termo de Consentimento Livre e Esclarecido, respeitando os aspectos éticos das pesquisas que envolvem seres humanos. A pesquisa foi aprovada pelo Comitê de Ética em Pesquisa do Hospital Universitário Pedro Ernesto (CEP/HUPE).

\section{A imagem corporal na Educação Física e na Nutrição}

A Sociologia trata o corpo como uma forma biológica moldada pela sociedade, o que o torna uma via de acesso para compreender os fenômenos sociais. Nessa perspectiva, as expressões corporais são reveladoras das lógicas socioculturais. Marcel Mauss ${ }^{35}$ compreende o corpo como um substrato produzido pela dimensão simbólica da sociedade. Desta forma, no âmago do movimento corporal, inscreve-se a lógica social. Ao estudarmos gestos, mímicas, o sofrimento, os divertimentos, os modos de andar, a aparência física, estudamos a própria cultura. ${ }^{35}$ Assim:

[...] a produção de sentidos sobre a imagem do corpo e a percepção que o sujeito tem do próprio corpo é, ao mesmo tempo, individual e coletiva, opera no social, mas não se limita a ele. Ela se desenvolve para além do indivíduo, das relações interpessoais ou dos complexos intrafamiliares, mesclando intensidades pré-verbais, afetos e códigos sociais de conduta (p. 480). ${ }^{36}$

Ou seja, o desenvolvimento da imagem corporal está intimamente ligado à estruturação da identidade no seio de um grupo social. ${ }^{37}$ Partindo do conceito de imagem corporal grupal, Schilder ${ }^{38}$ afirma que a preocupação com a dimensão corporal, apresentada pelas pessoas que cercam o indivíduo, interfere peremptoriamente na elaboração da imagem corporal desse indivíduo. Segundo o autor, as experiências e sensações obtidas em ações e reações às relações sociais também contribuem para a estruturação da imagem corporal. ${ }^{39}$ As questões relativas à imagem do corpo estão cada vez mais presentes no campo da saúde e influenciam na construção da identidade do sujeito, na percepção que este tem de seu próprio corpo (autoimagem) ou do que ele entende de saúde. ${ }^{40}$

A fim de ilustrar a questão, apresentamos a fala de uma aluna da Educação Física: "Tem a coisa do saudável, que gordo não é [...]”. Neste mesmo diapasão, Sabino (p. 197), ${ }^{41}$ em sua tese 
de doutorado, expõe que o indivíduo gordo, nas academias, é o mais desprezado. Uma das frequentadoras da academia, que foi entrevistada por ele, chegou a afirmar, proferindo lancinantes adjetivos: "Odeio gente gorda! Quem é gordo é preguiçoso, desleixado, descuidado, molenga, perdedor, fedorento!". O autor acrescenta que as culturas ocidentais no século XX passaram a demonizar a gordura. Como consequência, o status do gordo mudou:

Há um século, nos países ocidentais, os gordos eram amados; hoje, nos mesmo países, amam-se os magros. No tempo em que os ricos eram gordos, uma rotundidade razoável era muito bem vista. Ela era associada à saúde, à prosperidade, à respeitabilidade plausível, mas também ao capricho satisfeito... a magreza não sugeria mais do que a doença (o definhamento), a maldade ou a ambição desenfreada (p. 78). ${ }^{6}$

Da mesma forma, Contreras ${ }^{42}$ coloca que, nos séculos XVIII-XIX, esse corpo volumoso, que era desejado, além de associado também à saúde, boa reputação e abundância, estava relacionado à sexualidade da mulher. Ou seja, um corpo preparado para a maternidade e a constituição da família.

Entre os graduandos do curso de Nutrição, percebeu-se que o corpo magro é considerado relevante (e até determinante) para o sucesso profissional, visto que o corpo serve de marketing de si mesmo. ${ }^{43}$ Tal imagem corporal é tida como possibilidade de maior ou menor prosperidade e notoriedade, sendo importante para inserção no mercado de trabalho e aquisição de confiabilidade com o cliente. As alunas reforçaram que "tem que ser magra", principalmente aquelas que aspiram à atuação em clínica. Caso contrário, não há credibilidade com o cliente, que pode pensar como uma delas disse: "se ela não faz consigo mesma, como vai conseguir comigo?".

Fica evidente, assim, que os estudantes e profissionais do campo alimentar-nutricional ou da Educação Física são cobrados e culpabilizados com muito mais força. Uma vez que são conhecedores das práticas tidas como corretas, mais que todos, eles são vistos como alguém que tem a obrigação de agir e de viver em conformidade com essas normas cada dia mais institucionalizadas. ${ }^{44}$ Entre nutricionistas, por exemplo, o estigma ${ }^{\mathrm{d}}$ gerado pela obesidade afeta diretamente a relação com o trabalho, levando a dificuldades na relação com pacientes, além de produzir um sentimento de não pertencimento à profissão. Nesse sentido, a desaprovação do corpo gordo por pacientes e colegas da própria Nutrição - no contexto paradoxal de uma sociedade obesogênica, porém lipofóbica ${ }^{45}$ - gera situações de sofrimento no trabalho e nas demais relações sociais, ${ }^{46}$ pois a imagem do gordo é associada à pessoa que "não tem controle", "não tem limites", "vai além do necessário" e, portanto, não é uma pessoa confiável. ${ }^{47}$

d O estigma diz respeito a uma espécie de marca de valor negativo entranhada numa diferença socialmente construída. O processo de estigmatização se instala na expectativa dos atores que vivenciam dadas relações sociais - ou seja, a gordura corporal não é per si boa ou má, mas o olhar estabelecido pelos atores em relação é que imprime ao gordo a marca do indesejável e repugnante. ${ }^{47,57}$ 
O que percebemos é que, de fato, atualmente, a barriga (ou "ter gordurinhas sobrando") tem sido interpretada como símbolo de decadência e de não conformação com o mundo contemporâneo. Os que contam com peso a mais são, então, julgados de forma negativa e depreciativa por familiares, amigos, conhecidos e, inclusive, por profissionais de saúde. ${ }^{47}$ Corpo, cabelos e pele devem estar impecáveis, principalmente se o trabalho exigir a aparência como um "cartão de visitas" - como acontece com nutricionistas e professores de Educação Física. Essa conformidade na forma física é o que lhes vai conferir legitimidade enquanto profissional. ${ }^{43,48}$ Nessa linha, "vale registrar que, no Brasil, o mercado de trabalho opera um tipo de "seleção' que traduza lipofobia dominante" (p. 95). ${ }^{47}$ Esse modo de discriminação faz parte de toda a história das "pessoas gordas" sendo, nos dias atuais, particularmente reforçada e reiterada por meio dos processos de medicalização da vida cotidiana e estetização da saúde, ${ }^{49}$ nos quais o que é considerado saudável passa a ter relação direta com a forma física, nomeadamente, magra. ${ }^{47}$

É importante verificar que o culto à magreza e - consequentemente - o desprezo à gordura possuem uma carga de significações muito presente nas sociedades ocidentais. Dessa maneira, a magreza é tomada como sinônimo de "moderação, domínio de si, sucesso e adaptação social"; ao contrário, a gordura, a obesidade, é percebida como "um fracasso moral, uma incapacidade de se controlar, uma indisciplina ou uma tendência à preguiça” (p. 133) ${ }^{50}$ Isso justifica, por exemplo, os discursos das entrevistadas, tanto com relação a uma estigmatização do corpo gordo quanto para uma justificação para uma vida saudável.

Conforme abordamos no início deste artigo, os antropólogos são unânimes ao apontar a dimensão social do corpo. ${ }^{33,51-61}$ Para Geertz, ${ }^{62}$ a melhor forma de se aferir a vida social de um povo é através do estudo do corpo. É nele que encontramos marcas dos tabus, dos rituais, do sagrado, da magia e, conforme Novaes \& Vilhena ${ }^{63}$ acrescentam, do preconceito. É aí que entra a gordura. Em uma época em que classes ou "sociedades superavitárias" (p. 44) ${ }^{64}$ tendem a apresentar um número considerável de indivíduos com farto tecido adiposo (devido ao consumo excessivo de calorias e ao sedentarismo ${ }^{\mathrm{e}}$ ), paradoxalmente a imagem do gordo barrigudo é, cada vez mais, abominada. A "pessoa gorda” passa, não raro, a ser tolhida do convívio social pleno, sendo considerada doente, portadora de distúrbios psíquicos e fisiológicos. A silhueta gorda provoca apreciações bastante negativas e pejorativas. ${ }^{6}$

Os relatos de um estudo realizado com obesos mórbidos mostraram não só esses aspectos negativos da gordura (doença, falta de vontade para mudar, descontrole diante da comida, entre outros) como também as privações afetivas e o consequente isolamento do mundo público e o

e Sobre essa questão, Le Breton ${ }^{97}$ aponta que o fato de as tecnologias do trabalho substituírem, cada vez mais, as atividades que exigem força, cria um paradoxo com a atual valorização da muscularidade, visto que o dia a dia tende a poupar a utilização dos músculos, tendendo a atrofiá-los pelo desuso. 
"aprisionamento" em um mundo doméstico. Preso em função das próprias dificuldades em se locomover, dependência e vergonha em sair de casa pelo preconceito sofrido. ${ }^{65}$ Assim, a gordura assume o posto de inimigo número um da elegância e da felicidade. ${ }^{47}$

Nesse diapasão, parecem se repetir, na atualidade, com esta nova cartilha do corpo, práticas comuns no período medieval, ${ }^{66}$ como a demonização e imputação de culpa dos divergentes, seja de caráter religioso, étnico ou político. Deste modo,

[...] os obesos [...] parecem estar sendo transformados em uma espécie de "novoshereges" de uma emergente "Idade Mídia", em que veículos decomunicação encampam campanhas, visando à "melhoria" da saúdeda população através da redução da gordura corporal, incentivandoa população a alcançar uma determinada configuração corporalconsiderada ótima (p. 113). ${ }^{67}$

Quanto à imagem de corpo cultuada, Sabino ${ }^{41}$ diz que

[...] é a barriga, o abdômen - além do diâmetro muscular - o ponto de prova da excelência individual; é como se toda areté estivesse concentrada no centro do corpo, na região do umbigo. Uma "barriga tobogãa" ou "tanque de lavar roupa", repleta de ondulações, dobras e redobras musculosas, devido à ausência de gordura e presença constante de exercícios, é o símbolo supremo da saúde, da excelência e da beleza. Quanto mais barroca for a arquitetura abdominal, mais virtuoso será o indivíduo (p. 247).

Dito isso, percebe-se que as formas de lidar com o corpo produzem vínculos sociais, havendo cada vez menos tolerância para os desvios nos padrões estéticos socialmente estabelecidos. Nesse sentido, a gordura assume o papel de estigma e paradigma da feiura, onde as pessoas que estão acima do peso vivem uma crescente exclusão social, ${ }^{63}$ reverberando na autoimagem e autoestima desses indivíduos, que tendem a adoecer e sofrer em decorrência da obesidade e do estigma atrelado à gordura..$^{68,69}$

Segundo Mattos, ${ }^{69}$ vivemos em uma sociedade onde a gordura é tratada como inimiga íntima, um inimigo que, apesar de localizado dentro do corpo, está visível ao olhar do outro. Diante do apelo por um corpo saudável, identificado como corpo "sem gordura", o obeso é cada vez mais depreciado e patologizado. Em consonância com Mattos, Sabino (p. 152) ${ }^{23}$ afirma que "as representações de saúde em nossas sociedades têm sido atualmente relacionadas à ausência de adiposidade e à musculatura rígida e aparente”. A tolerância com a gordura se reduziu de forma tão drástica que esta se enquadra em uma categoria de exclusão na atualidade. O corpo gordo é visto como um corpo marcado pela falência moral e que, portanto, deve ser corrigido, a fim de valorizar a vida. ${ }^{70}$ 
É o corpo físico mostrando a identidade do sujeito, ou seja, seu caráter, competência e funções psicológicas e morais. ${ }^{71,72}$ Goldenberg (p. 9) ${ }^{73}$ sintetiza este sentimento numa proposta de slogan para tal mercado do corpo: "Não existem indivíduos gordos e feios, apenas indivíduos gordos e preguiçosos". Ao elucubrar sobre a "cultura do narcisismo", a autora apresenta a visão predominante no imaginário carioca:

Cada indivíduo é considerado responsável (e culpado) por sua juventude, beleza e saúde: só é feio quem quer e só envelhece quem não se cuida. Cada um deve buscar em si imperfeições que podem (e devem!) ser corrigidas. O corpo torna-se, também, capital, cercado de enormes investimentos (de tempo, dinheiro, entre outros). O corpo "em forma" se apresenta como um sucesso pessoal, ao qual qualquer mulher ou homem pode aspirar, se realmente se dedicar a isso (p. 9). ${ }^{73}$

Com relação ao julgamento social sobre a gordura, Fischler ${ }^{6}$ criou dois tipos fundamentais de estereótipos morais referentes à obesidade: os obesos benignos e os obesos malignos. Essa classificação varia de acordo com determinados padrões de comportamento. No primeiro grupo, o cientista social enquadra as pessoas de comportamento expansivo, extrovertido e brincalhão - o típico gordinho "boa praça", que parece querer desculpar-se pela inadequação física, compensando-a por meio da convivência agradável. Já no segundo, figuram os indivíduos que se negam a efetuar qualquer tipo de transação simbólica, com vistas a serem socialmente aceitos.

Não havendo qualquer tipo de restituição simbólica que possa despertar a piedade alheia, os gordos são mantidos excluídos, feito párias sociais, pois já não participam das regras do jogo social. Não à toa, na sociedade contemporânea, os obesos são denominados "malignos" ou "malditos" - como no jocoso termo empregado por Fischler. Possuem também um comportamento visto como depressivo, e por isso desprovido da obstinaçãa necessária para a contenção de suas medidas corporais. Enfim, sua imagem demonstra um certo desânimo perante a vida, e traduz fracasso no agenciamento do próprio corpo e dos seus limites (p. 21). ${ }^{63}$

Fischler ${ }^{6}$ trata a obesidade como um fenômeno social com diversas representações. Uma classificação dos estereótipos morais ligados aos obesos foi construída pelo autor, que assinala o caráter ambíguo que as representações sociais sobre a gordura assumem no imaginário atual. Os obesos recebem um tratamento contraditório, composto por um paradoxo importante: associam-se, aos gordos, estereótipos como simpatia e amabilidade; por outro lado, sua imagem inspira um sintoma social: a lipofobia. É nesse horror à gordura que se forja uma série de técnicas de emagrecimento, avalizadas pelos discursos que são construídos nas malhas da cultura do fitness e do bodybuilding.

Bauman $^{74,75}$ afirma que vivemos num mundo repleto de sinais confusos, propenso a mudar com rapidez e de forma imprevisível. Da mesma forma, podemos pensar a imagem corporal como um instrumento de uma cultura líquida e consumista que valoriza o prazer rápido, resultados 
imediatos e receitas já comprovadas de sucesso. O corpo tornou-se uma mercadoria que é trocada a todo momento, com o objetivo de estar sempre atualizado, na moda. A paciência e a incerteza são diminuídas - ou eliminadas - para que a imagem do corpo seja atlética e jovial.

A cultura do corpo também está ligada ao aspecto de consumo da sociedade atual, ratificada sobretudo pela mídia, que ressalta os padrões de beleza a serem seguidos e os benefícios estéticos adquiridos pelo cuidado com o corpo, de forma que "os indivíduos que conseguem ter uma correspondência com as imagens idealizadas de juventude, saúde, boa forma física e beleza possuem um valor econômico de troca mais elevado que aqueles que não podem ou não desejam se apropriar de tais imagens" (p. 133). ${ }^{50}$

Neste contexto, uma aluna do curso de Educação Física comentou durante a entrevista: “Tem muita discórdia na nossa área. Acho que é uma coisa muito complicada... de lidar com estes distúrbios de imagem corporal, é muito difícil...”. Foi então que outra aluna, que até o momento só nos escutava, disse:

Na Licenciatura a gente não vê muito isso, mas no bacharel é escancarado. Tipo, na minha academia a gente vê um bombadão que sabe... Tipo, no começo [perguntaram a ela]: "Qual professor você tem preferência para fazer avaliação?". Apontei aquele. Ai, depois de um tempo na academia que eu fui escolher o professor gordinho. Ai eu vi que o professor gordinho sabe montar série muito mais do que o bombadão. Mas a gente vê que primeiro a gente vai naquele que é melhor[fisicamente], porque a gente acha que ele sabe mais por ele tá mostrando no corpo dele.

Resultados de um estudo realizado com estudantes de Nutrição no Rio de Janeiro mostraram a insatisfação destas com seu corpo e o desejo de se adequar ao padrão de corpo ideal na nossa sociedade, mesmo entre as estudantes que apresentaram índice de massa corporal (IMC) adequado. No entanto, em se tratando de futuras nutricionistas, ou seja, profissionais da área de saúde, essa preocupação em atender às normas torna-se mais relevante já que, futuramente, poderão tratar de pessoas com comportamentos alimentares de risco. ${ }^{76}$ Além disso, os resultados apontam para uma reflexão necessária em torno do uso do IMC como forma de classificar o estado nutricional do sujeito, rotular o sujeito, mas que não é o objetivo deste artigo. ${ }^{65}$

De fato,

[...] atravessamos uma época na qual o culto à forma corporal ganhou amplitude inédita. Não é mais novidade: músculos definidos e inflados, tatuagens, piercings, implantes de silicone, botox, bronzeado artificial, cirurgias plásticas, estão constantemente presentes no cotidiano das grandes cidades e na mídia atual. Uma espécie de cultura do corpo - nos dois sentidos: da forma física e sistema subjetivo - vem se consolidando, ao menos em parte, nas sociedades complexas hodiernas, articulando padrões estéticos perseguidos por um crescente número de indivíduos insatisfeitos com seu corpo (p. 13). ${ }^{41}$ 
Consequentemente, manter esse corpo sempre adequado socialmente nos revela que, ao contrário dessa suposta liberdade de escolha, o que temos é um sinal de submissão do corpo aos padrões veiculados na mídia e reproduzidos pela sociedade ocidental contemporânea. ${ }^{77,78}$ Ainda, ao buscar a construção de um corpo mais adequado aos ideais estéticos hegemônicos ligados à adoração física vigente em nossa sociedade, acabamos por construir também uma ética singular diretamente radicada na estética. Temos, assim, o corpo como axis mundi.

Sabino $^{41}$ aponta que

[...] este processo tem conduzido indivíduos e grupos de determinados extratos sociais a buscarem uma perfeição física - obviamente inalcançável - radicada na proliferação de imagens, ideologias terapêuticas, métodos milagrosos e consumismo de produtos da indústria químico-farmacêutica como esteróides e suplementos alimentares, além de vitaminas e "fortificantes" dos mais variados tipos (p. 14).

A preocupação não apenas com a aparência, mas com a forma física - com o entalhe muscular lapidado a ferro, suor, exercícios, dor, dietas e mesmo cirurgias plásticas -, apesar de ser produzida coletivamente, torna-se carregada de investimento individual. Homens e mulheres famosos ${ }^{\mathrm{f}}$ anunciam na imprensa e nos programas de televisão as transformações corporais que decidiram realizar lançando mão de recursos tais como personal trainers, nutricionistas, cirurgiões plásticos e outros profissionais do rejuvenescimento, do embelezamento e da saúde - entendida atualmente como "boa forma física". ${ }^{41}$

Conversando sobre essas questões, duas alunas da Educação Física falaram:

[...] o corpo saudável, não é saúde em si.

É, e um corpo que não digo nem saudável, digo mais ousadamente ser esteticamente saudável aos olhos dos outros e dos dela próprio, porque ser saudável mesmo, às vezes, a gente vê que não é, entendeu? Você vể que tem muita gente aí, como a gente já falou aqui, que fuma, que bebe e é magrinho...

Na verdade, tem até pessoa que, tipo, não é saudável, não tem uma saúde, ele tem um corpo que visa isso que é imposto pela mídia, mas, no momento, ele não é saudável [...]. Ele, eu acho, é carente de vitamina, porque

f Alguns artistas "recém-sarados", dando dicas de preparação física, alimentação e suplementação em redes sociais e blogs (além daqueles que conquistaram fama através do "antes" e "depois" - sendo o antes um corpo com considerável percentual de gordura e o depois um corpo com músculos definidos e sobressaltados, além de baixa adiposidade), fazem com que muitos professores de Educação Física, nutricionistas e alunos destes cursos fiquem inconformados e preocupados com a possibilidade de indivíduos seguirem à risca - ferindo o Princípio da Individualidade Biológica - as dietas e treinamentos revelados na rede. Outro ponto que também gera polêmica é o quanto estes "modelos da boa forma" - por assim dizer - recebem pagamento após conquistar determinado número de seguidores (cada um com pelo menos 100 mil seguidores, alguns chegando a ultrapassar a casa dos $500 \mathrm{mil}$ ) em suas redes sociais, apenas por postar uma nova foto em suas páginas, divulgando determinada marca ou produto. Algumas quantias chegam a ultrapassar $\mathrm{R} \$ 5$ mil por foto. ${ }^{83}$ 
ele só foca em carboidrato, proteinas, essas coisas [...]. Tudo dele é extremamente... Ele não vai comer uma fruta, porque sabe que na fruta tem aquele açúcar que ele não... Que tá restringindo da dieta e já não gosta muito de ingerir...

É verdade. É muito difícil esse conceito, né? Da gente responder isso... É muito complexo porque saúde, gente, é muito difícil...

Neste âmbito, o corpo encontra-se diante de um crescente mercado que o tem como principal produto e produtor. "Estar em e manter a forma pode significar, neste fluxo somatófilo coletivo, sucesso pessoal, disciplina e talento para vencer, galgando os patamares da hierarquia social" (p. 14). ${ }^{41}$ A saúde torna-se um mandamento com efeito normalizador e adquire características de uma utopia, entendida como projeto que supera, por sua natureza praticamente religiosa - dado seu caráter universalista -, a ideologia. ${ }^{79}$ Esta, embora pretenda universalidade, é reconhecida pelos teóricos enquanto discurso particular, ou seja, discurso originário de uma parcela específica da sociedade, sendo, portanto, discurso parcial. No caso das práticas corporais ligadas primordialmente ao paradigma estético, tal utopia está atravessada por representações de beleza ancoradas nos valores individualistas da cultura contemporânea. ${ }^{41}$

Assim, mais que a racionalidade médica e seus modelos (normalidade-patologia ou vitalidadeenergia), é a estética o critério sociocultural maior de enquadramento dos sujeitos para determinar se realmente são "saudáveis", ou se precisam exercer alguma "atividade de saúde", através do estabelecimento de padrões rígidos de forma física. Neste caso, o comedimento, a temperança, tomados como mandamentos da saúde, estão mais ligados à boa forma do corpo que ao modelo doença/prevenção. ${ }^{80}$

O saudável ou normal é visto, conforme percepção de Canguilhem,${ }^{81}$ como uma variação social e não apenas de uma média estatística com fato biológico, resultado da atividade normativa do organismo em relação a seu meio. O homem só é sadio quando está adequado às regras. A cura, no entanto, não implica a saúde plena necessariamente, dentro dessa perspectiva. O homem normal saudável teria que se sentir capaz de reestabelecer continuamente sua saúde, sempre a ser buscada, o que, paradoxalmente, configuraria uma nova patologia, a patologia da saúde perfeita. ${ }^{81,82}$

Em consonância com esta concepção, Novaes \& Vilhena (p. 30) 63 $^{3}$ afirmam que "estar magra é positivado em qualquer contexto, discurso ou meio de sociabilidade. Estar magra é o melhor capital, portanto, a melhor forma de inclusão social e, por fim, a moeda de troca mais eficaz". Para as autoras, nos dias atuais, ser magra é um adjetivo da beleza. Esse ideal é constante e marca uma busca insaciável pela perfeição, isto é, pela aceitação do interior e/ou exterior do sujeito: 
[...] mesmo na ausência de todo excesso de peso ou na presença de uma silhueta que corresponde perfeitamente ao modelo valorizado, a população feminina é objeto de regulação e vigilância - sejam estes autoimpostos ou venham de fora - a fim de não se distanciar do ideal, ou ainda de garantir uma continuidade da questão interminável da imagem (p. 129)..50

Quanto aos alunos de Educação Física, notamos que o corpo com músculos definidos ${ }^{g}$ e hipertrofiados é motivo de prestígio, é um valor cultuado no campo, sendo um símbolo de distinção, com destaque para aqueles que estagiam em academias. ${ }^{83}$ Observa-se, então, que o "corpo da moda" é um dos maiores símbolos de inserção. É no corpo que estão impressas as marcas que o distinguem, tanto cultural quanto socialmente, por meio de seus adornos e símbolos. "No palco da cultura, à mercê de seus signos, o corpo ultrapassa os limites do biológico - sua versão mecânica -, e torna-se personagem/ator social, travestindo-se de seu aparato simbólico" (p. 10). ${ }^{63}$ Segundo as autoras, "a cultura atual preconiza que estejamos bem para poder expor ao máximo o corpo. Hoje em dia vale muito mais um braço sarado do que roupas caríssimas" (p. 11).

A busca pelo corpo ideal associado à beleza e à magreza provém de inúmeras influências, e suas consequências não estão em menor quadro. A quantidade de imagens e literatura sobre o assunto mostra um modelo único de beleza, gerando insatisfação constante sobre o próprio corpo que, por sua vez, é fruto de inúmeras doenças, como ansiedade e depressão, além de diversas práticas que colocam a saúde em risco. É o caso, também, de doenças como anorexia e bulimia, problemas alimentares relacionados a uma preocupação excessiva com relação ao corpo. Além disso, essa preocupação excessiva com o corpo "não está menos associada a práticas alimentares e de atividades físicas potencialmente nocivas para a saúde, tais como o efeito sanfona (perdas e ganhos de peso alternados e repetitivos) e diversas práticas insalubres de perda de peso" (p. 204). ${ }^{84}$

Deste modo, as academias de musculação "surgem como usinas de produção da forma, fabricando corpos para serem consumidos pela lógica do mercado" (p. 145). ${ }^{23}$ Assim, esses ambientes, com suas indicações de substâncias químicas - suplementos alimentares e esteroides anabolizantes -, seu conjunto de máquinas cada vez mais desenvolvidas e informatizadas, operam como uma espécie de fábrica do corpo. Há, nestas instituições disciplinares, uma verdadeira linha de montagem da forma, na qual o indivíduo é acoplado às máquinas e levado a experimentar todo tipo de inovações químicas para moldar sua massa muscular. O termo massa, muito usado pelos fisiculturistas, remete diretamente a esta dimensão reificante do mundo do trabalho. Algo informe sobre o qual a razão científica se debruça executando seus objetivos de conformação estética. ${ }^{41}$

g Definir a musculatura não significa apenas fazê-la crescer (hipertrofiar), mas também reduzir o porcentual de gordura corporal para que as fibras musculares se tornem visíveis. ${ }^{41}$ 
Massa é categoria recorrente no cotidiano dos discentes de Educação Física e praticantes de musculação. Aquisição de massa muscular equivale à aquisição de um bem, de um capital biológico que deve ser investido, revestido de significado por intermédio de um processo classificatório que confere valor e sentido àquele conteúdo muscular inicialmente indistinto. Este sentido é produzido através da articulação de um sistema de representações coletivas que pode ser compreendido pela análise da publicidade voltada para esse público específico. ${ }^{41}$

Sabino ${ }^{41}$ complementa:

Para "malhar", é preciso ter tempo e uma quantia razoável de dinheiro a ser investido na aparência. Esta surge como uma espécie de vitrine onde as supostas virtudes individuais são apresentadas para um "público consumidor" eventual que possa trazer tanto lucro econômico quanto simbólico. A lógica de gerenciamento empresarial toma conta do cotidiano individual, gerenciando suas vidas em um processo de marketing pessoal que acaba por coisificar a existência em uma nova forma de tratar o corpo e a vida. Corpo-objeto, corpoespetáculo, corpo-capital a ser investido, “corpo-brasão, símbolo de um pertencimento, efígie feita signo" [...] de uma classe, de um estilo de vida, de um ethos. Este processo que consiste na tentativa de transformação do mundo em uma grande classe média, um grande meio termo, é o corolário de americanização - ou ao menos da interpretação local da cultura e dos símbolos postos sob a égide norte-americana - do modus vivendi de grande parte do Ocidente atual e peculiar à classe média em ascensão do litoral brasileiro que sonha em transformar-se em réplica de Miami ou Los Angeles (p. 247).

"Malhar" o corpo é investir a própria vida em rituais de passagem. Não se pode deixar de demarcar que o verbo malhar remete à ideia de castigar, de bater, de desgastar alguém ou alguma coisa. $\mathrm{O}$ antropólogo francês Van Gennep ${ }^{85}$ concluiu que a maioria dos ritos analisados observava uma sequência que incluía "separação", "transição" e "incorporação". Para o indivíduo que é leigo tornar-se sacerdote, é preciso executar cerimônias, isto é, atos de um gênero especial com uma orientação mental preestabelecida. Entre o mundo profano e o mundo sagrado, há incompatibilidade, a tal ponto que a passagem de um ao outro não pode ser feita sem os ritos de passagem. Da mesma forma ocorre com os estudantes de Educação Física e Nutrição, que passam a malhar o corpo para adquirir a imagem do profissional de Educação Física ou do nutricionista. Se não malhar o corpo, não há status de profissional da área.

Turner $^{86}$ também afirma que os ritos de passagem permitem a transição entre estados, isto é, a passagem de uma condição a outra. O próprio autor cita as profissões e ocupações como exemplos. A fase inicial do rito de passagem envolve a separação e o afastamento do estudante de graduação dos indivíduos ou grupos que não buscam ou não têm a imagem corporal hegemônica. A fase final, por sua vez, é aquela na qual o estudante encontra-se numa condição estável, em virtude da qual tem direitos e obrigações de um tipo estrutural claramente definido, e dele se espera um 
comportamento de acordo com certas normas costumeiras e certos padrões éticos. Na linguagem de Bourdieu, ${ }^{87}$ seria o momento em que se torna um agente de conservação no campo.

De tal modo, as academias assumem o papel de verdadeiras fábricas e mecânicas de corpos. O processo de produção do corpo saudável pode ser classificado em uma gradação que vai da matéria-prima (o corpo em seu estado natural), passando pelo investimento (de produtos químicos e adaptações às máquinas de exercícios), até o produto final (um corpo reluzente, musculoso e “saudável”), investido de magia e poder conferido pelas classificações totêmicas do mundo dos marombeiros ${ }^{\mathrm{h}}{ }^{41}$

Esses gostos reiteram a distinção social, ${ }^{88}$ traduzindo-se em signos exteriores, sendo o corpo um elemento de prestígio, ou seja, a aparência física como um signo de distinção por excelência dos grupos desta pesquisa. Neste processo de construção corporal da distinção, a musculatura rígida e evidente acoplada a um baixo percentual de gordura assume um sinal de distinção social e poder dentro do campo, onde ter o corpo trabalhado disciplinarmente por máquinas e exercícios físicos (e, em alguns casos, suplementos alimentares) é diferente de ter um corpo de trabalhador braçal. ${ }^{89}$

Esse caráter sistemático e metódico de submeter-se constantemente ao escrutínio da fita métrica e ao espelho - em um processo que "exige uma conduta ascética, racional e individualista" (p. $174)^{23}$ - é similar ao analisado por Max Weber ${ }^{90} \mathrm{em} A$ ética protestante e o espírito do capitalismo.

Weber $^{90}$ afirma que o catolicismo dificultava o desenvolvimento e a prosperidade econômica ao condenar o lucro, ao passo que o protestantismo valorizava a meritocracia e o trabalho como bênçãos espirituais e produtoras de riqueza. Assim, o autor destacou a ascese intramundana como a mudança de condutas, comportamentos e pensamentos dos homens que permitiu o surgimento do capitalismo industrial. Utilizando um raciocínio-lógico do tipo analogia, podemos afirmar que a entrada no campo da Educação Física e da Nutrição como estudante de graduação e futuro profissional é um momento de encontro com um conjunto de práticas e discursos que reiteram a

h Marombeiro, na cidade do Rio de Janeiro, tornou-se sinônimo de frequentador assíduo de academias de musculação, o mesmo que "rato de academia". Esta palavra origina-se de maromba: vara utilizada por acrobatas para equilibrar-se na maroma - corda na qual caminha. Maromba também pode significar o(s) peso(s) - quilagem ou carga externa, para citar sinônimos - com o(s) qual(is) o funâmbulo se mantém em equilíbrio. Como no treinamento de força ou de resistência muscular localizada (RML) são utilizadas barras com pesos removíveis, ou não, nas extremidades, podemos analogamente associar as imagens do homem que anda na corda bamba, utilizando o peso da maromba para se equilibrar com aquele que utiliza os pesos para otimizar sua forma física e força muscular. ${ }^{23,41}$ Novaes e Vilhena ${ }^{63}$ apontam que o termo malhar não é usado aleatoriamente. "Malha-se como se malha com o ferro quente..." (p. 27), segundo as autoras, não sendo à toa a profunda tirania com que tratam o corpo, privando-o de alimentos, mortificando-o e submetendo-o a exercícios físicos torturantes. Ressalta-se que o termo malhar vem entrando em desuso nas academias do Rio de Janeiro, onde a palavra "treinar" detém, atualmente, um valor simbólico mais significativo. Como o linguajar vai mudando, escuta-se muito mais "eu vou treinar" (o que capitaliza a fala do sujeito e, por conseguinte, o próprio sujeito), do que o outrora tão repetido e valorizado "eu vou malhar". ${ }^{83}$ Vale acrescentar que a construção do corpo adquiriu tamanho destaque na cultura hodierna que Courtine (p. 82) ${ }^{98}$ chega a afirmar que o marombeiro "não anda; ele conduz seu corpo exibindo-o como objeto imponente". 
ascese intramundana através da construção da imagem corporal ideal. Trata-se do que Andrieu ${ }^{91,92}$ nomeia de bioascese.

\section{Considerações finais}

Esta pesquisa permitiu perceber a imposição oriunda de uma representação social sobre o corpo na contemporaneidade, amplamente difundida na mídia a respeito do corpo trabalhado pela musculação e dieta. Nesse contexto, os graduandos em Educação Física e em Nutrição devem apresentar responsabilidade quanto à prática de bons hábitos alimentares e um estilo de vida mais saudável e devem mostrar, na imagem de seus corpos, uma aparência saudável.

Não é um aprisionamento do sujeito somente ao corpo, mas à fita métrica, às academias, aos produtos de beleza e às cirurgias plásticas. Aprisionamento a um modelo físico reproduzido socialmente como ideal e hegemônico. Para alguns autores, isso é chamado de "culpabilização" ou "responsabilização" do sujeito em uma sociedade que transfere para o próprio sujeito o compromisso rígido de manter um padrão de saúde e boa forma, excluindo o valor dos determinantes da saúde..$^{93,94}$

Para Lechopier ${ }^{95}$ desde os anos 1950, as abordagens científicas dominantes na saúde pública consistiram na identificação dos fatores de risco. Essa abordagem do fator de risco foi criticada por sua falta de visão social dos fenômenos populacionais. As ciências sociais críticas questionam os fundamentos e a ideologia da saúde pública. Há estudos críticos de variados antropólogos, sociólogos, historiadores e filósofos, mas muitos continuam a inspirar-se na análise foucaultiana do biopoder. ${ }^{12,14,96}$

Assim, não só as políticas de saúde inseridas num contexto macropolítico e macroeconômico, mas as práticas e discursos cotidianos foram estudados e criticados como modos de subjetivação, controle e dominação. As malhas do poder atuam para capturar, orientar, determinar, interceptar, modelar, controlar e assegurar os gestos, as condutas, as opiniões e os discursos dos seres vivos. Isso fica evidente nos estudantes da área de saúde, sobretudo aqueles por nós estudados, revelando um discurso na lógica de um dispositivo de poder produtor de subjetividades corporificadas na glória do corpo sarado e magro.

O que nos cabe refletir não é sobre a existência de um padrão, mas sobre a maneira com que esses jovens estão lidando quando não conseguem atendê-lo. Ser gordo ou magro, loiro ou moreno, alto ou baixo, ter cabelos lisos ou anelados são características que fazem parte de uma mesma sociedade.

Vimos, assim, a Educação Física e a Nutrição como dois pilares desta contemplação, sendo, muitas vezes, os agentes da área da saúde, atores que reproduzem a imagem do corpo socialmente 
cultuada como ideal: livre de gordura e com músculos esculturalmente torneados. Percebemos, então, nos casos observados, forte representação social a respeito do comportamento e do modelo de corpo preponderante entre os estudantes das duas áreas, indicando em muitos momentos um discurso bem estruturado e incisivo acerca daqueles que fogem do padrão hegemônico. Podemos perceber um julgamento de valores que estigmatizam os padrões desviantes e valorizam as práticas que potencializam os aspectos corporais em níveis que, mesmo fora das condições normais de hipertrofia muscular e gordura, colocam a estética muitas vezes como status social diferenciado, acima das questões de saúde.

Cabe perceber se essas representações sociais a respeito do corpo nessas disciplinas são reflexo do imaginário social que vem sendo compartilhado amplamente na mídia e que ganha as ruas, academias e praias, e em que medida a atuação (e formação) desses profissionais está inserida na produção desses padrões estruturados socialmente. Isso se traduz na necessidade de serem trabalhados ao longo da graduação os significados e os simbolismos do corpo e a relação com esse ideal de primazia da beleza como algo padronizado.

\section{Referências}

1. Bauman Z. O mal-estar da pós-modernidade. Rio de Janeiro: Zahar; 1998.

2. Bauman Z. Modernidade e ambivalência. Rio de Janeiro: Zahar; 1999.

3. Le Breton D. A sociologia do corpo. 2. ed. Petrópolis: Vozes; 2007.

4. Mauss M. Sociologia e antropologia. São Paulo: Cosac \& Naify; 2003.

5. Sacramento I, Cruz CS. A patologização da obesidade: endereçamentos da moralidade corporal contemporânea em um programa de TV. In: Lerner K, Sacramento I, organizadores. Saúde e jornalismo: interfaces contemporâneas. Rio de Janeiro: Fiocruz; 2014.

6. Fischler C. Obeso benigno, obeso maligno. In: Sant'Anna DB, organizadora. Políticas do corpo: elementos para uma história das práticas corporais. São Paulo: Estação Liberdade; 1995.

7. Foucault M. Microfísica do poder. Rio de Janeiro: Graal; 2000.

8. Lipovetsky G, Serroy J. A cultura-mundo: resposta a uma sociedade desorientada. São Paulo: Companhia das Letras; 2011.

9. Luz MT, Sabino C, Mattos RS, Ferla AA, Andres B, Alba RD, et al. Contribuição ao estudo do imaginário social contemporâneo: retórica e imagens das biociências em periódicos de divulgação científica. Interface 2013; 17(47):901-912.

10. Luz M, Machado A, Dall'Alba R, Ferla AA. Potencial retórico das capas de revistas de divulgação científica face ao imaginário de vida e saúde: uma proposta metodológica de análise. Interface. 2016. (in press).

11. Foucault M. Histoire de la sexualité: la volonté de savoir. Paris: Gallimard; 1976. 
12. Foucault M.Il Faut défendre la société: Cours au Collège de France 1976. Paris: Seuil; 1997.

13. Foucault M. Sécurité, territoire, population: Cours au Collège de France (1977-1978). Paris: Seuil; 2004.

14. Foucault M.Naissance de la biopolitique: Cours au Collège de France (1978-1979). Paris: Seuil; 2004.

15. Luz MT. O impacto da epidemia de HIV/AIDS nas representações sociais. Saúde, Sexo e Educação 1998; 6(13):6-11.

16. Machado AS. O cérebro no imaginário social da divulgação científica das Biociências: a retórica sobre a saúde e a vida nas capas da Revisa Mente e Cérebro [dissertação]. Porto Alegre: Universidade Federal do Rio Grande do Sul; 2015.

17. Spink MJP. Representações sociais: questionando o estado da arte. Psicologia \& Sociedade 1996; 8(2):166-186.

18. A estética do risco... Revista Veja 6 nov. 2013; 2346.

19. Leme A. A nova forma de magreza. Revista Veja 2 nov. 2013; 2346: 84-93.

20. Medrado B. Textos em cena: a mídia como prática discursiva. In: Spink MJ, organizadora. Práticas discursivas e produção de sentidos no cotidiano: aproximações teóricas e metodológicas. 2. ed. São Paulo: Cortez; 2000.

21. Freitas R. Corpo e consumo: a estética carioca. In: Villaça N, Góes F, Kosovski E, organizadores. Que corpo é esse? Novas perspectivas. Rio de Janeiro: Mauad; 1999.

22. Ribeiro CR. O corpo masculino nos discursos de homens e da revista Men's Health. In: Strey MN, Von Mühlen BK, Kohn KC, organizadoras. Caminhos de homens: gênero e movimentos. v. 9. Porto Alegre: EdiPUCRS; 2014.

23. Sabino C. Anabolizantes: drogas de Apolo. In: Goldenberg M, organizadora. Nu e vestido: dez antropólogos revelam a cultura do corpo carioca. 2. ed. Rio de Janeiro: Record; 2007.

24. Sautchuk CE. A medida da gordura: o interno e o íntimo na academia de ginástica. Mana 2007; 13(1):153-179.

25. Weber M. A “objetividade” do conhecimento nas ciências sociais. In: Cohn G, organizador. Max Weber: sociologia. 5. ed. São Paulo: Ática; 1991.

26. Weber M. Conceitos básicos de sociologia. 4. ed. São Paulo: Centauro; 2005.

27. Becker HS. Los extraños: Sociologia de la desviación. Buenos Aires: Tiempo Contemporáneo; 1971.

28. Becker HS. Métodos de pesquisas em Ciências Sociais. São Paulo: Hucitec; 1994.

29. Malinowski B. Antropologia. In: Durham ER, organizador. Coleção grandes cientistas sociais. São Paulo: Ática; 1986.

30. Orlandi EP. Análise de discurso: princípios e procedimentos. Campinas, SP: Pontes; 2001.

31. Goldenberg M. A arte de pesquisar: como fazer pesquisa qualitativa em Ciências Sociais. 11. ed. Rio de Janeiro: Record; 2009.

32. Gell A. The art of anthropology: essays and diagrams. London: Athlone; 1998.

33. Sperber D. Le savoir des anthropologues. Paris: Hermann; 1982. 
34. Wacquant LJD. Corps et ame: carnets ethnographiques d' um aprrenti boxeur. Paris: Agone; 2002.

35. Mauss M. Les techniques du corps. Paris: PUF; 1950.

36. Ferreira FR. A produção de sentidos sobre a imagem do corpo. Interface 2008; 12(26):471-483.

37. Tavares MCGCF. Imagem corporal: conceito e desenvolvimento. São Paulo: Manole; 2003.

38. Schilder P. A imagem do corpo: as energias construtivas da psique. 2. ed. São Paulo: Martins Fontes; 1994.

39. Secchi K, Camargo BV, Bertoldo RB. Percepção da imagem corporal e representações sociais do corpo. Psicologia: teoria e pesquisa 2009; 25(2):229-236.

40. Ferreira FR. Ciência, arte e cultura no corpo: a construção de sentidos sobre o corpo a partir das cirurgias plásticas. Curitiba, PR: CRV; 2011.

41. Sabino C. O peso da forma: cotidiano e uso de drogas entre fisiculturistas [tese]. Rio de Janeiro: Universidade Federal do Rio de Janeiro; 2004.

42. Contreras J. La obesidad: una perspectiva sociocultural. Formación continuada en nutrición y obesidad 2002; 5(6):275-286.

43. Santos LA. O corpo, o comer e a comida: um estudo sobre as práticas corporais e alimentares no mundo contemporâneo. Salvador: Edufba; 2008.

44. Castro JBP, Carvalho MCVS, Ferreira FR, Prado SD. "Faça o que eu digo, mas não faça o que eu faço!": a décalage como ferramenta para compreensão de práticas corporais e alimentares. Revista de Nutrição 2015; 28(1):99-108.

45. Neves AS, Mendonça ALO. Alterações na identidade social do obeso: do estigma ao fat pride. Demetra 2014; 9(3):619-631.

46. Araújo KL, Pena PGL, Freitas MCS, Diez-Garcia RW. Estigma do nutricionista com obesidade no mundo do trabalho. Revista de Nutrição 2015; 28(6): 569-579.

47. Campos SS, Ferreira FR, Seixas CM, Prado SD, Carvalho MCVS, Kraemer FB. Num relance de olhar... a estigmatização das pessoas gordas: do passado aos dias de hoje. Revista HUPE 2015; 14(3):90-96.

48. Berger M. "Felicidade é entrar num vestido P": o culto ao corpo na sociedade urbana contemporânea. Cadernos de Campo 2010; 19(19):69-90.

49. Ferreira FR, Freitas PMSS, Wollz LEB. O culto ao corpo, a estetização da saúde e o papel do nutricionista. In: Prado SD, Freitas RF, Ferreira FR, Carvalho MCVS, organizadores. Alimentação, consumo e cultura. v. 1. Curitiba, PR: CRV; 2013. Série Sabor Metrópole.

50. Vinette S. Image corporelle et minceur: à la poursuite d'un idéal élusif. Reflets 2001; 7(1):129-151.

51. Boas F. Anthropology and modern life. New York: Dover Publications; 1988.

52. Boas F. Primitive art. New York: Dover Publications; 2010.

53. Csordas TJ. Corpo/Significado/Cura. Porto Alegre: UFRGS; 2008.

54. Douglas M. Purity and danger: concepts of pollution and taboo. Londres: Routledge; 1966.

55. Eliade M. Le Sacré et le Profane. Paris: Gallimard; 1987. 
56. Evans-Prichard E. The nuer: a description of the modes of livelihood and political institutions of a Nilotic people. New York: Oxford Press; 1969.

57. Goffman E. Stigmate. Paris: Editions de Minuit; 1975.

58. Le Breton D. Anthropologie du corps et modernité. Paris: PUF; 2008.

59. Lévi-Strauss C. La pensée sauvage. Paris: Plon; 1962.

60. Malinowski B. Argonautas do Pacífico Ocidental: um relato do empreendimento e da aventura dos nativos nos Arquipélagos da Nova Guiné Melanésia. São Paulo: Abril Cultural; 1976.

61. Strathern M. Property, substance and effect: anthropological essays on persons and things. London: Athlone; 1999.

62. Geertz C. A interpretação das culturas. Rio de Janeiro: LTC; 1989.

63. Novaes JV, Vilhena J. De Cinderela a moura torta: sobre a relação mulher, beleza e feiura. Interações 2003; 8(15):9-36.

64. Rodrigues JC. Cultura e ser humano. In: Rocha E, organizador. Cultura e imaginário: interpretação de filmes e pesquisa de ideias. Rio de Janeiro: Mauad; 1998.

65. Passos MD. Sentidos e significados da obesidade mórbida no processo de cuidar: um estudo no Centro de Referência em Obesidade [tese]. Rio de Janeiro: Universidade do Estado do Rio de Janeiro; 2015.

66. Richards J. Sexo, desvio e danação: as minorias na Idade Média. Rio de Janeiro: Zahar; 1993.

67. Palma A, Assis M, Vilaça MM, Almeida MN. Os “pesos” de ser obeso: traços fascistas no ideário de saúde contemporâneo. Movimento 2012; 18(4):99-119.

68. Mattos RS, Luz MT. Sobrevivendo ao estigma da gordura: um estudo socioantropológico sobre obesidade. Physis 2009; 19(2):489-507.

69. Mattos RS. Sobrevivendo ao estigma da gordura. São Paulo: Vetor; 2012.

70. Mattos RS. Sou gordo, sou anormal? Arquivos em Movimento 2007; 3(2):153-173.

71. Le Breton D. A sociologia do corpo. 4. ed. Petrópolis, RJ: Vozes; 2010.

72. Vilhena J, Medeiros S, Novaes JV. A violência da imagem: estética, feminino e contemporaneidade. Revista Mal-Estar e Subjetividade 2005; 5(1):109-144.

73. Goldenberg M, organizadora. Nu e vestido: dez antropólogos revelam a cultura do corpo carioca. 2. ed. Rio de Janeiro: Record; 2007.

74. Bauman Z. L'amour liquide: de la fragilité des liens entre les hommes. Paris: Fayard; 2010.

75. Bauman Z. La vie liquide. Paris: Fayard; 2013.

76. Bosi MLM, Luiz RR, Morgado CMC, Costa MLS, Carvalho RJ. Autopercepção da imagem corporal entre estudantes de nutrição: um estudo no município do Rio de Janeiro. Jornal Brasileiro de Psiquiatria 2006; 55(2):108-113.

77. Maroun K, Vieira V. Corpo: uma mercadoria na pós-modernidade. Psicologia em Revista 2008; 14(2):171-186.

78. Passos MD. Imagem corporal e suas representações sociais: um estudo com adolescentes do município do Rio de Janeiro [dissertação]. Rio de Janeiro: Universidade do Estado do Rio de Janeiro; 2011. 
79. Sfez L. A saúde perfeita: crítica de uma nova utopia. São Paulo: Edições Loyola; 1996.

80. Luz MT. As novas formas da saúde: práticas, representações e valores culturais na sociedade contemporânea. Revista Brasileira de Saúde da Família 2008; 9:8-19.

81. Canguilhem G. Normal e patológico. In: Canguilhem G. O conhecimento da vida. Rio de Janeiro: Forense Universitária; 2012.

82. Coelho MTAD, Almeida Filho N. Normal-patológico, saúde-doença: revisitando Canguilhem. Physis 1999; 9(1):13-36.

83. Castro JBP. Faça o que eu digo, mas não o que eu faço: uma análise de discurso sobre práticas alimentares e corporais entre graduandos em Educação Física e Nutrição [dissertação]. Rio de Janeiro: Universidade do Estado do Rio de Janeiro; 2014.

84. Baril G, Paquette M-C, Gendreau M. Le culte de la minceur et la gestion sociale du risque: le cas de la Charte québécoise pour une image corporelle saine et diversifiée. Sociologie et Sociétés 2011; 43(1):201-222.

85. Van Gennep A. The rites of passage. London: Routledge \& Keagan Paul; 1960.

86. Turner V. Floresta de símbolos: aspectos do ritual Ndembu. Niterói: EdUFF; 2005.

87. Bourdieu P. Méditations pascaliennes. Paris: Éditions du Seuil; 1977.

88. Bourdieu P. A distinção: crítica social do julgamento. São Paulo: Edusp; Porto Alegre: Zouk; 2008.

89. Boltanski L. As classes sociais e o corpo. 2. ed. Rio de Janeiro: Graal; 1984.

90. Weber M. L'éthique protestante et l'esprit du capitalisme. Paris: Gallimard; 2004.

91. Andrieu B. Les cultes du corps. Paris: L’Harmattan; 1995.

92. Andrieu B. La Nouvelle philosophie du corps. Paris: Érès; 2002.

93. Nogueira L, Palma A. Reflexões acerca das políticas de promoção de atividade física e saúde: uma questão histórica. Revista Brasileira de Ciências do Esporte 2003; 24(3):103-119.

94. World Health Organization. Declaração política do Rio sobre determinantes sociais da saúde. Rio de Janeiro: WHO; 2011.

95. Lechopier N. Quatro tensões na saúde pública. Estudos Avançados 2015; 29(83):209-231.

96. Foucault M. Les Anormaux. Cours au Collège de France (1974-1975). Paris: Seuil; 1999.

97. Le Breton D. Adeus ao corpo: antropologia e sociedade. Campinas, SP: Papirus; 2003.

98. Courtine J-J. Os stakhanovistas do narcisismo: body-building e puritanismo ostentatório na cultura americana do corpo. In: Sant'Anna DB, organizadora. Políticas do corpo: elementos para uma história das práticas corporais. São Paulo: Estação Liberdade; 1995.

Recebido: 13/3/2016

Revisado: 19/7/2016

Aceito: 02/8/2016 